\title{
CORRELATION OF MATHEMATICS AND SCIENCE ${ }^{1}$
}

CLARENCE E. COMSTOCK

Bradley Polytechnic Institute, Peoria, Ill.

A foreword in regard to the point of view of this paper may be of service. I take it that any interplay between the school courses in different subjects to be of lasting value must spring from underlying relations which serve as essential links binding those subjects into one. This interplay must result in mutual helpfulness, or else it fails of its purpose. Science is not to be lugged into mathematics as an outsider, nor is mathematics to be foisted upon science as an added burden. If it can be found that the one is indispensable to the other, then and only then can there be any reasonableness in the remarks offered in this paper. I trust that you will find the position of the speaker a thousand miles removed from that of the teacher in a grammar school of a decade or two ago, who, holding up a bird before her bright-eyed pupils, asked them to count its eyes, its legs, its toes, its wings, etc.; and then propounded these elucidating questions: "How many eyes and toes does the birdie have? If it had three more toes, how many would it have in all? If you multiply the number of its eyes by the number of its toes, what would the result be?"

From the point of view of the scientist, mathematics is a tool of science; from the point of view of the mathematician, science is a field for the application of mathematical truth; from the viewpoint of both, mathematics is a method of science. In fact, it may be called the ultimate method of science; the more perfectly a science is developed, the more mathematical does it become, until it reaches a stage when it is classified as mathematics. Away in the past was it when the sciences of arithmetic and geometry assumed their mathematical names. In comparatively recent years mechanics has reached this same development,

${ }^{1}$ Paper read before the Department of Science Instruction of the National Educational Association,, Asbury Park, N. J., July, r905. 
and is now classed as mathematics. The various branches of physical science, astronomy, meteorology, and chemistry are rapidly being subjugated by this method of exact investigation; while the biological, mental, and social sciences are still in a very unmathematical state of evolution. The method is of such power and value that it must itself be made the subject of investigation; its inner relations must be scrutinized, and the inevitability of its conclusions established on a firm basis. There has thus arisen the most wonderful and enthralling science of them all - that science which defies definition, for it transcends all limiting bounds; that science which rears unto itself in imagination a palace whose walls and turrets know not the limiting thraldom of time and space; the queen science of them all, abstract mathematics.

If this view of the relation of mathematics and science in general be true, then it would seem that there should be a corresponding intimacy between the courses offered in schools and colleges for instruction in these subjects. Of course, there is and always has been a certain degree of interplay between such courses; but the query obtrudes itself: Cannot a more vital and effective relation be maintained? It is easy to see that the study of mathematics is absolutely essential to anything but a very superficial knowledge of the sciences. Physical laws of action, the laws of chemical action, and the laws of the formation of crystals are derived from observed data and verified by the methods of the higher mathematics. It is the very language of science. To read Shakespeare, one needs to know the meaning and the use of words. To read Hilton's Chrystallography, Preston's Theory of Light, or the works of the masters in chemistry, a very considerable acquaintance with mathematics is a prerequisite, if they are not to be sealed books.

But it is not to the scientific man alone that mathematics is indispensable; the engineering profession, that vast army of workers in applied science, is equally in need of such knowledge.

The minute differentiation of the engineering profession which has in very recent times resulted in the separation of the countless pursuits which require technical education, has opened an ever- 
increasing field for the operation of human activities. The specialists who concern themselves with problems of sanitation, water supply, highway construction, marine architecture, bridgebuilding, the telephone, tannery, refinery, and manufactory, the machinist and the designer - all these, and a thousand more, call for expert technical knowledge. It is becoming more and more apparent that success in these technical professions is conditioned upon such knowledge and training. In a recent meeting of the National Association of Electrical Engineers it was the generally expressed conviction that one prerequisite for success in that profession is a thorough training in mathematics. It is clear that science is an indispensable part of modern civilization. Of course, science is not the only element in education, for culture is broader and must include much more. And yet it is certainly true that when so large a part of modern human activity is based upon scientific knowledge, it becomes necessary that the schools furnish ample opportunity for adequate instruction in science. I here use the word "science" to include both natural and mathematical science.

An examination into the teaching of science in the schools and colleges of America for the past two hundred years or so reveals some interesting things. Until very recently the study of science was considered of little importance. The amount of mathematics required in courses in astronomy and natural philosophy in early American times can be inferred from the amount of mathematics taught. At Harvard in 1643 the mathematical course began in the senior year, and consisted of arithmetic, geometry, and astronomy. The science of algebra was unknown on the continent. The importance ascribed to mathematics is shown by the time devoted to different studies: philosophy, Io hours; Greek, 6; rhetoric, 6; oriental languages, 4; mathematics, 2.

In 1726 natural philosophy was given in the junior year, but was metaphysicad rather than mathematical in form; nor could it be otherwise, as arithmetic and geometry were still taught in the senior year. By I742 algebra was taught at Yale, and the mathematical studies were put earlier in the course. The freshmen had arithmetic and algebra; the sophomores, geometry; the juniors, 
mathematics (probably trigonometry), conic sections, and natural philosophy. By I 766 fluxions had been introduced as an optional study.

Since 1816 the whole of arithmetic has been required for entrance to Harvard. The catalogue of 1825 adds algebra through simple equations, with roots, powers, and the progressions. In I843 a little introductory geometry was added. The mathematical course at Harvard in I8I8 was as follows: freshmen - algebra and geometry; sophomores - algebra and trigonometry, with application to heights and distances and navigation; juniors - natural philosophy, astronomy, mensuration of surfaces and solids, surveying; seniors - conic sections, spherical geometry.

The physics taught in the colleges of the eighteenth century required very little knowledge of mathematics. To master Olmsted's Natural Philosophy, which was extensively used during the middle of the nineteenth century, a fair knowledge of algebra and geometry, with a very little trigonometry, was sufficient. Almost no mathematics was used in the treatment of heat and electricity, whereas now calculus is commonly used in college courses in physics. In former days, when the college course (classical) chiefly trained for the so-called learned professions, the student found very little or no field in which his mathematics was needed. There was no application for it in his serious work, and it was therefore studied purely for a cultural value, as a means of training the general logical and reasoning powers of the mind. But with the growth of scientific study, and the rise of scientific courses and technical schools, the study of mathematics has assumed a much more important rôle. It now becomes an essential prerequisite to the future work of a large number of students; it becomes highly functional rather than decorative or gymnastic. We begin to learn that the real worth of mathematical study is not the general training of the mind, but the training of the mind in mathematical thought, to the end that our ignorance of the phenomena about us may be lessened and our impotence in the face of the forces which surround us may be reduced.

One would naturally suppose that such an important change 
in function ought to have considerable influence in determining the form in which mathematics is presented to the student. It is having some effect in the dethronement of the mathematical fetish; the increasing tendency to make mathematical study optional is traceable, I think, in some degree to this cause. And yet the courses themselves are too little affected. In most cases the vital connection between mathematics and science is not dwelt upon, and the student fails to find any place for his mathematics in his scheme of life. He learns to cipher, but sees in it nothing but an artificial pastime. Now, ciphering is of value when ciphering leads to some desired end. The ability to solve a quadratic equation in itself is worthless; it is only when the equation is solved for some other end that the ability to solve it has meaning.

It appears to be true that under present conditions the student is not properly prepared in mathematics for his work in science. A training which does not furnish the student with the best and most efficient mathematical equipment for such work is certainly misdirected. It would seem to me that the statement just made must be acceded to, no matter what view is taken as to the end of mathematical study in the school. This brings us to the main question of this paper: How can courses in mathematics be organized to better meet the needs of science?

A speaker in a recent convention of electrical engineers said: "What we need most is a common-sense mathematics." This voices what seems to me to be an imperative need. We need a mathematics stripped of its artificialities and direct in its purpose. It is often a far cry from the mathematics of the schools to the mathematics of actuality. Our texts are filled with cunningly devised exercises which are remarkable for nothing but their intricacy, tangles, and labyrinths, the like of which are found nowhere save in the brain of the drill-master. They are meaningless devices, "which," to use Beltrami's language, "make the student's mind sterile through the everlasting exercises which are of no use except to produce a new Arcadia where indolence is veiled under the form of useless activity."

Such artificial exercises, it is true, afford a certain training, but a training in nothing else than dexterity in the manipulation 
of impossible formulæ - "brain-spinning" as the Germans call it. Now, although a high degree of dexterity in the use of algebraic forms is essential to successful study of higher mathematics and science, yet that dexterity is not the main thing to be sought. That which is of the most importance in mathematics as well as in science is the interpretation of the mathematical forms used. In the higher mathematics there are countless forms that do appear and call for transformation or simplification. Let such forms be used as exercises in lower reaches of algebra, instead of the useless forms so prevalent in our texts. A few illustrations may make clearer this distinction between mathematics as it is taught and mathematics as it is used.

A recently published algebra tells us that "an unknown quantity is usually denoted by one of the last letters of the alphabet, as $x, y, z . "$ Now, this is far from being the fact, unless you restrict the field to elementary algebra. Open any book on astronomy, physics, chemistry, meteorology, or higher mathematics, and the exact contrary is found to be the case. Such equations as these meet the eye on every page:

$$
\begin{aligned}
& \frac{a}{b}=\frac{\sin A}{\sin B} . \\
& A=\pi r^{2} ; \\
& s=v t-\frac{1}{2} g t^{2} ; \\
& c=\frac{E}{r+R} ; \\
& p=a e ; \\
& w=c \log \frac{v_{2}}{v_{1}} ; \\
& v=e^{a y+B x} ; \\
& I=\int p^{2} d M .
\end{aligned}
$$

In fact, in the higher mathematics $x$ and $y$ have a meaning largely restricted to the Cartesian co-ordinates. The constant use of the $x, y$ method is harmful in that it relieves the student of the necessity of scanning an equation, for the unknown for which the equation is to be solved is at once recognized, and the solution 
follows mechanically; whereas some attention must be given to such an equation as

$$
D=\frac{w}{v} \quad \text { or } \quad s=v t-\frac{\mathrm{I}}{2} g t^{2} .
$$

And right here lies a fundamental of great importance. From the standpoint of science, an equation is looked upon as stating a relation between certain numbers of co-ordinate importance. The significance of the equation rests in this, that if some of these numbers be known, the others can be found. Now in order that algebraic training shall be of advantage to the student of science, this view should be firmly impressed upon him. Too often the equation is regarded as a formal puzzle to be solved, rather than an essential relation to be perceived. It is in the interpretation of the equation and the result of its solution that true algebraic thought resides. It were better to solve a limited number of equations understandingly than a large number mechanically. Nor will this thorough consideration of a few examples prevent the acquiring of dexterity in solution. For if all steps are understood to have a meaning, and are thoroughly mastered in their relations, the very clearness of perception thus produced will induce a better performance. Clear seeing is more than half in the doing.

Again, the scholastic method so prominent in all our texts produces the result pointed out by a recent scientific writer: "The regular textbooks of mathematics rather perplex than assist the chemical student who seeks a short road to a working knowledge of higher mathematics." The scientific student needs a thorough insight into mathematical methods, as well as a working knowledge of them; but to obtain this it is not necessary for him to go through all the artificial rubbish with which so many works are incumbered. A man can gain his exercise and develop his mathematical muscle among the green fields and wooded lanes of God's universe, rather than on the tread-wheel in a man-made gymnasium. I protest against a condition of affairs because of which it is possible to say that instruction in mathematics befogs the issue and cheats the scientific student out of the very results for which he began his study of mathematics. 
As a second element in the improvement of mathematical training, I would suggest that the best mathematical methods be used as early as possible. As mathematical science advances, it produces better and better methods for solving given problems. It was a long step in advance when multiplication was substituted for a large class of additions; and one can hardly express the debt the world owes to Napier and Briggs for logarithms. Descartes, Newton, and Leibnitz have forged for us titanic instruments with which to work. The progress of civilization is conditioned to some extent upon the application of these discoveries to the needs of mankind. Without a murmur, the most of us replace our tallow dip with the incandescent fiber, the messenger post with the copper wire, the copper wire with the wireless telegraph. But there is a great outcry when any of us propose to use logarithms in arithmetic, trigonometry in geometry, or calculus in the secondary school. I even know of a college professor of mathematics who lives in a world long since outgrown, for, as he says: "Long ago I discarded from my teaching the doctrine of negative numbers." But the history of mathematics is but the story of the victorious march of new and better methods: new ideas and processes replace the old. New discoveries increase efficiency. A search in the algebras of a generation ago would not reveal the presence of the remainder theorem, the graph, or the determinant. Only within late years has the ratio definition of the trigonometric functions become current in our teaching. It is a waste of time and of perspicuity to teach simultaneous equations without graphs and determinants, or the geometry of the triangle without trigonometric functions. The calculus offers instant relief among the antiquities of college algebra and analytic geometry. Says Professor Jules Tannery, of the Ecole Normale Supérieure, in speaking of the use of integral calculus in the secondary school: "After these lessons, say, nine or ten, one half-hour is sufficient to establish the expressions for all the volumes of elementary geometry." Why not use the best instruments the mathematician can turn out, at the first opportunity that offers? Says one, because the student cannot understand all the fundamental theory of the subject; especially is this urged in the case of calculus. But would you 
throw the equation out of algebra because it is impossible to prove to the child that every rational, integral equation has a root? Shall we give up multiplication because we cannot construct a definition that will include all cases of multiplication? Indeed, we never get to the bottom of anything. What is number? No one can tell us, not even Professor Peano. We are often led away by that will-o'-the-wisp, thoroughness, until we lose our pupils in the maze and perplexities of the more advanced reaches of a subject much too abstract to be within their powers of comprehension; whereas the beginnings of trigonometry, analytics, calculus, and differential equations open a field of clear and simple ideas, well within their power of understanding. It is folly to insist that a problem be worked by a certain method of elementary arithmetic, when it can be done in a better way by algebra or calculus. It is high time to strike off such shackles as those with which Euclid bound elementary geometry, the ruler, and the compass.

The sciences - astronomy, physics, chemistry, and mechanics - can make powerful use of these higher forms of tools. What waste of effort to treat the composition and resolution of forces without the help of the trigonometric functions! The ideas of differentiation and integration are wonderfully productive in the hands of science. We can best benefit the student of science by giving him an early mastery of these powerful agents. He must have that mastery if he is to have anything but a superficial glimpse of the fields of science, or if he is to be of material service in the application of that science to the subjugation of the world.

But there is a third way in which mathematical course may better fit for service - the consideration of real scientific problems. The stating of a problem in algebraic form, its solution, and the interpretation of the result is rightly regarded a valuable part of algebraic study. All our algebras contain long lists of such problems, and it is to the character of these problems that I wish to call attention. They are for the most part manufactured, unnatural. A few illustrations, taken from an algebra published in I904, will serve to make this point clearer: "A lady purchased 20 yards of one kind of cloth, and 50 yards of another, for \$30. She could have purchased 30 yards of the first kind and 20 yards 
of the second for \$23. What was the price of each?" This is artificial, as no lady would ever meet such a problem. Or this : "A fishing-rod consists of two parts. The length of the upper part is 5-7 that of the lower part. The sum of 9 times the length of the upper part and 13 times the lower part exceeds I I times the length of the whole rod by 36 inches. Find the length of the rod." This was evidently manufactured for consumption in simultaneous equations. It is thoroughly unnatural and impossible, and is a mere rehabiting of that old problem supposed to have been given by Euclid in 300 B. C. : "A horse and a donkey, laden with corn, were walking together. The horse said to the donkey: 'If you gave me one measure of corn, I should carry twice as much as you, but if I gave you one, we should carry equal burdens.' Tell me their burdens, $\mathrm{O}$ most learned master of geometry." As a contrast to these problems consider two. "A stone dropped from a balloon rising at the rate of $3^{2}$ feet a second reaches the ground in 17 seconds. How high above the ground was the balloon when the stone was dropped?" "It is desired to find the height of a town or hill above a level plane. A 6-foot pole is set up, and the point determined where the line connecting the tops of the town and pole strikes the ground. The pole is used at this point, and a second point determined in the same way. The distance between these two points is measured. What is the height of the town?"

Objection is often made to this sort of a problem, that it brings in matter that is unfamiliar to the pupil, and it is said that in the first class, such as deal with ages, money, capital, partnership, legacies, "there is an especial advantage in that the attention is not distracted from the algebraic side of the problem while the acquaintance with algebra is as yet slight." After considerable experience in using both kinds, I find that students will solve the second class as readily as the first kind. They may require more thought, but this is to be commended; for the thought is productive thought. Respect for mathematics can hardly be maintained if its interpretation is given in terms of how old is Ann, and if it seems to have no more serious purpose than the solution of a mathematical rebus. It were much better to 
present the dignity of a mathematics evolved to solve real problems; and the world is full of such problems - problems of number, mensuration, statics, and dynamics, which need offer no distracting ideas. The two problems just mentioned, the balloon and the town problems, were solved with little difficulty by a class in first-year algebra, and several solutions were given. These natural, real, vital problems should be spread through the whole course of school and college mathematics. I cannot refrain from quoting a rather humorous problem found by my calculus class. The problem was no doubt an attempt to be practical: "A train starting from a station has after $t$ hours a speed of $t^{3}-2 \mathrm{I} t^{2}$ $+80 t$ miles per hour. Find its distance from the station; time when it repassed the station; the distance the train had traveled when it passed the station the last time. The train passed the station after starting the first time at the rate of I,200 miles an hour."

Mathematics is an abstract science. Its glory is that it can proceed to the profoundest generalizations without appeal to the world of the senses; and yet its ideas at the start are abstractions from that world. From one point of view, geometry is a system of logic entirely independent of a physical world; yet our Euclidean geometry is but a classification of observed facts and the generalization arising therefrom. The difficulties of a geometrical proposition may often be dissipated by the study of a model. In our geometrical teaching we are making constant use of diagram and model. The transit has come to be of service for furnishing material for the class in trigonometry to work upon. But this is about the extent of any appeal to the world of the senses, made in our classes in mathematics. To me this seems unfortunate, especially in view of the steady pressure by which mathematical study is being crowded into the earlier years of a student's growth. It appears to be undeniable that capacity for abstract thought develops late. Now, it takes thirty-six or forty-eight weeks to cover the same ground that was covered in twelve or sixteen weeks when geometry was a college study. Although we have lengthened the time for the boy, we have made but little alteration in the method, forgetful of the fact that "boys are not men of a 
lesser growth." Boys are men in the process of making, and there the likeness ends. The impetus given to the study of physical, chemical, and biological phenomena by the recourse to actual observation and experiment has been most remarkable. It would seem to me that a similar vitalizing movement may be of service to mathematics. There are dangers connected with the use of experimental methods in instruction, and laboratory work has often been carried to absurd lengths; and yet the study of the world at first hand can never cease to be the fountain-head of all serious study. I firmly believe that the study of mathematical relations in concrete form by students of elementary mathematics is of great value. Last fall $\mathrm{I}$ asked a class beginning algebra to cut from a strip of cardboard Io by $\mathrm{I} / 2$ inches a piece containing I2 square inches. Not more than two out of a class of thirty could do it. I found that very few of them had ever used a scale or a tape-line. All of them could answer the abstract question: "The area of a triangle is 15 square inches; one side is $3 \frac{1}{2}$ inches; what is the other side?" The divorce between the abstract and the concrete had been so complete in their case that the connection had been entirely lost. This is but an instance of a widespread condition - the failure to embody mathematics.

As a fourth means of meeting the needs of a scientific age, then, I would make the suggestion that more use of actual experiment and observation be made in our classes in mathematics. You will pardon a reference to some work with which I am intimately connected. I make it with the thought that a bit of testimony from actual experience may be of service in this connection. In Bradley Polytechnic Institute we have introduced such experimental work to a greater or less degree for five or six years. The results lead us to increase rather than diminish such work. There are certain experiments usually performed in the physics laboratory that are really mathematical in form. But little physical knowledge is needed for their performance. A number of these are now performed in our mathematical classes; credit is given for reports upon them by both the departments of mathematics and physics. It is not so much the purpose to teach physics as to teach mathematics in a setting of physics. In the beginning 
algebra class the balance and lever are used; observations on the movement of a street car are made. The law of falling bodies, $s=1 / 2 g t^{2}$, is tested by a stone dropped from the tower. Heights and distances are calculated, and then actually measured. This gives confidence in mathematical processes and control in their application. In the second year, devoted especially to geometry, the work is a little more serious. Careful reports are required on about thirty experiments, chosen because of the geometrical ideas involved. Among these may be mentioned reflection of light and formation of images in plane mirrors, refraction of light by prism, composition and resolution of forces, and inclined plane involving use of trigonometric functions. The same care and accuracy that are demanded in the physics laboratory are insisted upon. From this kind of work the student gets a more real and intimate hold on the meaning of geometric and algebraic truth. It is often objected that there is a waste of time in such work; it is said that "the geometrical results can be arrived at more expeditiously in other ways." Is it not true, however, that the geometrical result is not the only thing to be sought. Fully as important is the setting, the value, and the utility of the fact. A boy may not see the use of filing a piece of metal to the exact diameter demanded by the teacher; but when he finds that the piece is too large or too small, by the thousandth of an inch, to fit into the engine or machine he is helping to build, and has to be made over or thrown away, he learns something of great value. Just so the student who finds that exceeding care must be taken if the lines determining the image in the mirror are actually to meet on his drawing, learns something from his own experience that the insistence of the teacher can seldom impart.

Our experience seems to point to two definite things. We are often told that, "no matter how geometry be taught, the student must be able to pass the entrance examinations set by the colleges and the universities." Now, while I demur to the view that the typical entrance examination is either a fair or a desirable test of mathematical ability, I am willing to admit that, since the examinations exist, they must be met. We determined to make a test in the examination just held two weeks ago. There were two 
classes in geometry to be examined: One, a class of boys, was given the entrance examination for one of the large eastern universities; the other, a class of girls, was given an entrance examination of one of our best-known woman's colleges. The instructor in charge of the classes did not see the papers until they were given him at the time of the examination. The class had reviewed but a very small portion of the work of the year. There were in the classes a few students whose general standing as students would debar them from being college timber. Of those who were at all eligible for going up for college entrance, but two out of forty were unable to pass, and those two were good students who always fell down on examination from emotional or nervous reasons. Some of the papers were of a very high order. At least this can be said. After a training involving a large number of physical experiments, they were no less able to handle the reasoning of the abstract originals than are those who are not so trained, while at the same time they have in addition a real and intimate knowledge of mathematics as revealed in natural phenomena.

The other point of interest comes as testimony from the classes in physics. Said a boy who entered the physics class from another school, to his instructor in physics: "You talk to us as though you expected us to know mathematics, and I seem to be the only one that has very much difficulty in using mathematics." Now, this is a crucial test.

This is the real service that instruction in mathematics may render to science. Not that science be taught as science in classes of mathematics, but that the language in which science speaks shall be taught, and as far as possible mastered, so that the science teacher may proceed with his teaching unhampered by the inability of the student to understand the language in which he can most clearly and accurately put the ideas and laws with which he is dealing.

By such means it would seem to me possible to make mathematics a more efficient instrument in the hand of the student of science or engineering. Nor would the student who is to become the pure-mathematician receive a less worthy training. It is from a rich mathematical soil that the great mathematicians of the 
future will arise. It is Fourier who said: "The deeper study of nature is the most fruitful source of mathematical study;" and we remember that it was the effort to solve some particular problem of science that gave birth to most of the great advances in mathematics. In our study of mathematics, the queen of science, let us not get too far from that world which, to quote Kelvin and Tait, "is replete with astonishing theorems of pure mathematics such as rarely fall to the lot of those mathematicians who confine themselves to pure analysis or geometry, instead of allowing themselves to be led into the rich and beautiful fields of mathematical truth which lie in the way of physical research." 